\title{
Investigating the Age of Becoming a Smoker and Its Related Factors Among Student Population: a Web- based Study
}

\section{Peyman Habibi}

Neyshabur University of Medical Sciences

\section{Farhad Shekari}

Tabriz Medical University: Tabriz University of Medical Sciences

Asghar mohammadpoorasl

Tabriz Medical University: Tabriz University of Medical Sciences

Vijay Kumar Chattu

University of Toronto Ontario Institute for Studies in Education

Neda Gilani ( $\nabla$ neda.gilani@gmail.com )

Tabriz Medical University: Tabriz University of Medical Sciences https://orcid.org/0000-0002-53990277

Research

Keywords: Smoker, Age, Web-based, Electronic questionnaire, Student, Iran

Posted Date: June 15th, 2021

DOl: https://doi.org/10.21203/rs.3.rs-599763/v1

License: (c) (i) This work is licensed under a Creative Commons Attribution 4.0 International License. Read Full License 


\section{Abstract}

Background: Preventing smoking at an early age is one of the primary solutions to reduce the likelihood of becoming a smoker in adulthood. This study aimed to investigate the age of becoming a smoker and its related factors and to assess the change in the age trend of becoming a smoker among students in Iran.

Methods: A cross-sectional web-based survey was performed from July to August 2019 in Tabriz, Iran. A proportional cluster sampling in all universities of the city was implemented, according to the number of students in each university. The data were collected from 3640 students via an online survey questionnaire. Data analyses were performed by using Stata (version 16). The statistical level of significance was set at 0.05 .

Results: The average ( \pm SD) age of becoming a smoker in the students was 18.8 (6 2.6) years. The age of becoming a smoker has decreased over time. A linear regression model showed that male and undergraduate students become smokers 0.77 and 0.50 years earlier than other students, respectively ( $P$ $<0.001$ ). Older age, being single, and later smoking initiation increase the average age of becoming a smoker by 0.2 years, 0.77 years, and 0.54 years, respectively $(P<0.001)$.

Conclusion: The age of becoming a smoker has decreased over time. Prevention programs should target males and undergraduate students. Furthermore, since students have become smokers earlier than their peers in the past, there is a direct relationship between smoking initiation and the age of becoming a smoker.

\section{Introduction}

The epidemic of Tobacco smoking is one of the world's biggest public health threats with high rates of mortality and morbidities. It is also known as the most widely used addictive substance globally and one of the leading causes of death (1). Cigarette addiction is a problem that occurs in all walks of life, from illiterate individuals to highly educated ones. Considering the potential role of educated people in the development of society, tobacco addiction among educated individuals would have very severe repercussions on society. The early death of millions of people, especially in the most productive period of their life, causes irreparable damage to every society. Studies show that cigarette consumption is on the rise among young people (2-4). The prevalence of cigarette consumption estimated by WHO is 24.1 million (6.1\%) in the population aged 13 to 15.

Furthermore, the prevalence of smoking among Iranian adolescents aged 6 to 18 years is also estimated to be $5.9 \%$ (7.5\% in boys and $4.2 \%$ in girls) (5). Early smoking-onset age is a risk factor that makes it more problematic. As studies indicated, the onset of cigarette smoking typically occurs during early adolescence (6). According to the US Department of Health and Human Services, almost $90 \%$ of adults who smoke regularly smoked their first cigarette by age 18 years (7). The odds of smoking is three-to-one in adulthood by delaying smoking until 18 . Until the age of 24 , the odds of smoking are even reduced to 
twenty-to-one (8). According to a National Survey of Drug Use and Health report in the United States, $88.5 \%$ of smokers start smoking before age 21 and $96.8 \%$ before 25 (8). Besides, delaying smoking initiation will minimize the risk of transitioning to a regular or daily tobacco use and increase the chances of quitting successfully among regular smokers (8). therefore, if the age of smoking initiation decreases in a society, the concerns are far greater than in a society where people initiate smoking at later ages. Becoming a smoker at an early age, in other words, the early exposure to nicotine and the following dependence on a cigarette, can reduce brain activity and negatively affect concentration and memory (8, 9).

Furthermore, increased daily smoking in adulthood, long-term cigarette smoking, lower chance of smoking cessation, and higher mortality rates are among the other consequences related to cigarette smoking addiction at an early age $(10,11)$. some studies have shown that the period during which smokers become regular smokers is between 18 and $21(12,13)$. the National Survey on Drug Use and Health has indicated that the age of regular daily smoking for $47 \%$ and $80 \%$ of adult smokers was before 18 and 21 , respectively (14).

It is important to remember that starting to smoke or smoking would not always result in becoming a smoker (15). To the best of our knowledge and understanding, this is the first research to look at the age at which people start smoking. Previous studies conducted in Iran and other countries on the status of smoking at young ages have focused more on the age of onset of smoking or the first cigarette smoking, as well as the prevalence of smoking among individuals involved with smoking $(16,17)$, hence the age of becoming smoker, and the age trend of cigarette addiction over time has remained unclear. To examine the age of smoking, we must have a proper definition of a smoker. There are various definitions for a smoker in studies (18-20). For example, a person who smokes 100 cigarettes in the lifetime has considered a smoker in some sources (21). Smoking alone or purchasing cigarettes indicates being a smoker in other research (22). In the current study, a person who buys a cigarette for personal consumption was considered a smoker. The present study investigates the age trend of becoming a smoker by comparing the age of becoming a smoker among different age groups and the associated risk factors of becoming a smoker among Students of all Tabriz universities.

\section{Methods}

\subsection{Study design and participation}

A web-based cross-sectional study was carried out from July to August 2019 among students of all nine (9) universities in Tabriz, Iran. Out of about 15,000 students selected by random proportional cluster sampling, 3780 students have received an electronic questionnaire, of which 3640 questionnaires were completed. The ethics committee at Tabriz University of Medical Sciences approved the study protocol. All of the questions in the research tool were carefully designed using scientific evidence and expert opinions that had previously been used in other studies. To determine validity, the questionnaire and a response form for quantitative comments was distributed to 5 experts in the field of cigarette smoking 
and 6 experts in methodology and instrumentation to assess the questionnaire's relevance and transparency. A pilot study with 30 students was conducted to determine reliability. We developed the final questionnaire in Google Form after receiving responses and revising the questionnaire. All students were invited to participate in the study, and they were given a short link to the questionnaire so that they could complete it online. Besides, Telegram and Instagram apps were also used to engage more students in the study. To ensure wider circulation, the group administrators and members of the student networks and groups in Tabriz universities were contacted and asked to share the questionnaire links in their groups so that students could complete the survey if they agreed to participate in the study. The participants' participation was entirely voluntary, and their anonymity was guaranteed. The number of study participants from each university was tracked as the questionnaires were completed to ensure fair representation and preserve the sample size from all of the participating universities. When a university's predetermined number of participants was reached, the researchers stopped sampling from that university and concentrated their efforts on universities with insufficient sample sizes.

\subsection{Measurement}

\subsection{1. demographic characteristics}

Demographic characteristics included age, gender, marital status, and educational levels.

\subsubsection{Cigarette smoking status}

All the respondents were asked about the history of their smoking status. Based on their responses the respondents were classified into three stages of smoking/tobacco consumption:

1. Never smoker: students who have never tried cigarettes.

2. Experimenter: included students who have just tried or experimented with cigarette smoking, those who smoked irregularly in the past but did not smoke in the present time, those with regular smoking in the past but quitted at present, and those who smoke on a non-daily basis at the time of the survey.

3. Smoker: students who regularly smoked daily.

Notably, Students were also asked to identify which members of their family are a smoker.

\subsubsection{Age of smoking initiation}

All students were asked to identify at what age they first started smoking. Age of becoming a smoker: By saying. "age of becoming smoker," we mean the time when a person transitions from borrowing cigarettes to purchasing for personal consumption. This definition has already been used in a previous study (22). Therefore, students who regularly smoked were asked: At what age did you start buying cigarettes for your consumption?

\subsubsection{High-risk behaviors}

The section included questions on Alcohol abuse in the last 30 days (yes / no), Hookah use (I have never used it, I have only tried it, I smoke hookah at least once a month) and Substance abuse (includes Opium, 
cannabis, ecstasy, heroin, methamphetamine, crystal or glass, Ritalin, grass/marijuana). The participants were also asked about the intake of products containing energizers (such as testosterone, methandienone, growth hormone, insulin, somatropin, clenbuterol, etc.) were recorded and their responses were coded as yes/no. Besides, screening questions on self-harm (e.g. cutting with razor objects, burning or scalding, pulling hair, punching or kicking or banging on the wall, peeling skin, scratching the skin with a sharp object, biting yourself or pinching yourself that causes redness or bruising, etc.) were also recorded and coded as yes/no).

\subsection{Statistical analysis}

To compare the age of becoming a smoker in the different groups, the independent T-test and one-way analysis of variance (ANOVA) were used. To evaluate the differences between the groups, the GamesHowell post hoc test was used. The variables associated with the age of being a smoker were also investigated using univariate and multivariate linear regression analysis. The data was analyzed using STATA software (version 16).

\section{Results}

The average age of participants in this study was $22.84 \pm 3.66$ years (age range: $18-47$ years) of which 2034 (55.7\%) were males and 1615 (44.3\%) were females. Most of the participants, about $90 \%$ (3247 students), were single. Also, about $70 \%$ of the participants were undergraduates. Furthermore, almost $47 \%$ of students had never used a hookah, and only $11.5 \%$ of them smoked hookah regularly (at least once a month). Moreover, about 11 percent of respondents reported consuming alcohol in the past 30 days. Also, $13 \%$ of the participants in the study had a history of substance abuse. About $26 \%$ of participants reported at least one type of self-harm. Approximately $32 \%$ of respondents reported that at least one member of their family smoke cigarette. Besides, about $24 \%$ of the participants were smokers, and $21 \%$ had smoked in the past. Also, the mean age of the first attempt to smoke was 17.64 years (Table 1). 
Table 1

Demographic characteristics, smoking status, and high-risk behaviors among students by gender

\begin{tabular}{|c|c|c|c|}
\hline \multirow[t]{2}{*}{ Variables } & total & Female & Male \\
\hline & $\mathbf{N}(\%)$ & $1615(44.3 \%)$ & $2034(55.7 \%)$ \\
\hline Age(years) ${ }^{*}$ & $22.84( \pm 3.66)$ & 22.89 & 22.81 \\
\hline \multicolumn{4}{|l|}{ Marital status } \\
\hline single & $3262(90.2 \%)$ & $1371(86.4 \%)$ & $1876(93.1 \%)$ \\
\hline married & $355(9.8 \%)$ & $216(13.6 \%)$ & $138(6.9 \%)$ \\
\hline \multicolumn{4}{|l|}{ Education level } \\
\hline Associate & $74(2.0 \%)$ & $35(2.2 \%)$ & $39(1.9 \%)$ \\
\hline Undergraduate & $2513(69.4 \%)$ & $1114(71.3 \%)$ & $1369(67.9 \%)$ \\
\hline Postgraduate & $525(14.5 \%)$ & $238(14.8 \%)$ & $287(14.2 \%)$ \\
\hline Doctorate (Ph.D. \& MD) & $509(14.1 \%)$ & $187(11.7 \%)$ & $322(16 \%)$ \\
\hline \multicolumn{4}{|l|}{ Hookah smoking } \\
\hline Never & $1700(46.6 \%)$ & $1002(62.4 \%)$ & $685(33.8 \%)$ \\
\hline Experimenter & $1528(41.9 \%)$ & $543(33.8 \%)$ & $981(48.4 \%)$ \\
\hline Regular (at least once per month) & $421(11.5 \%)$ & $62(3.9 \%)$ & $359(17.7 \%)$ \\
\hline \multicolumn{4}{|l|}{ Smoker in the family } \\
\hline Yes & $1148(31.5)$ & $523(32.5 \%)$ & $618(30.6 \%)$ \\
\hline No & $2497(68.5)$ & $1088(67.5 \%)$ & $1399(69.4 \%)$ \\
\hline \multicolumn{4}{|c|}{ Alcohol consumption (in the last 30 days) } \\
\hline Yes & $412(11.3 \%)$ & $75(4.7 \%)$ & $337(16.7 \%)$ \\
\hline No & $3224(88.7 \%)$ & $1528(95.3 \%)$ & $1679(83.3 \%)$ \\
\hline \multicolumn{4}{|l|}{ Substance abuse (ever) } \\
\hline Yes & $444(13.0 \%)$ & $86(5.7 \%)$ & $358(18.9 \%)$ \\
\hline No & $2981(87.0 \%)$ & $1433(94.3 \%)$ & $1532(81.1 \%)$ \\
\hline \multicolumn{4}{|l|}{ Self-injury } \\
\hline Yes & $950(26.1 \%)$ & $440(27.5 \%)$ & $505(24.9 \%)$ \\
\hline No & $2693(73.9 \%)$ & $1161(72.5 \%)$ & $1520(75.1 \%)$ \\
\hline
\end{tabular}




\begin{tabular}{|llll|}
\hline Variables & $\begin{array}{l}\text { total } \\
\mathbf{N}(\%)\end{array}$ & $\begin{array}{l}\text { Female } \\
\mathbf{1 6 1 5}(\mathbf{4 4 . 3 \%})\end{array}$ & \begin{tabular}{l} 
2034 (55.7\%) \\
\hline Smoking status
\end{tabular} \\
\hline Non-smoker & $1993(55.1 \%)$ & $1151(72 \%)$ & $842(41.7 \%)$ \\
\hline Experimenter smoking & $769(21.3 \%)$ & $327(20.5 \%)$ & $442(21.9 \%)$ \\
\hline Smoker & $855(23.6 \%)$ & $121(7.6 \%)$ & $734(36.4 \%)$ \\
\hline Age of inanition smoking* & $17.64( \pm 3.26)$ & $18.78(( \pm 3.45)$ & $17.28(( \pm 3.11)$ \\
\hline * mean \pm SD & & & \\
\hline
\end{tabular}

The average age of becoming a smoker based on the Independent sample t-test was 18.8 with a standard deviation of \pm 2.6 (18.6 \pm 2.5 for males and $19.9 \pm 2.9$ for females) (Table 2$)$.

Table 2

Age of becoming smoker by gender in participants

\begin{tabular}{|c|c|c|c|c|c|c|c|}
\hline \multirow[t]{2}{*}{ Variable } & \multicolumn{2}{|l|}{ Total } & \multicolumn{2}{|l|}{ Male } & \multicolumn{2}{|c|}{ Female } & \multirow{2}{*}{$\begin{array}{l}\mathrm{p}- \\
\text { value }\end{array}$} \\
\hline & $\begin{array}{c}\text { Mean } \\
\text { (SD) }\end{array}$ & $\begin{array}{l}\text { Median } \\
\text { (min- } \\
\text { max) }\end{array}$ & $\begin{array}{l}\text { Mean } \\
\text { (SD) }\end{array}$ & $\begin{array}{l}\text { Median } \\
\text { (min- } \\
\text { max) }\end{array}$ & $\begin{array}{l}\text { Mean } \\
\text { (SD) }\end{array}$ & $\begin{array}{l}\text { Median } \\
\text { (min- } \\
\text { max) }\end{array}$ & \\
\hline $\begin{array}{l}\text { Age of becoming } \\
\text { smoker }\end{array}$ & $\begin{array}{l}18.8 \\
(2.6)\end{array}$ & $\begin{array}{l}19.0 \\
(12-35)\end{array}$ & $\begin{array}{l}18.6 \\
(2.5)\end{array}$ & $\begin{array}{l}18.0 \\
(12-28)\end{array}$ & $\begin{array}{l}19.9 \\
(2.9)\end{array}$ & $\begin{array}{l}20.0 \\
(12-35)\end{array}$ & $<$. \\
\hline
\end{tabular}

The bar chart in Fig. 1 illustrates the age trend of regular smoking among students over time, showing a downward trend in the 'age of regular smoking' which indicates younger students have become smokers earlier than older ones. Except in the age group under 20 years, in other age groups, the average age of the first regular smoking in men is less than that of women. In the under-20 age group, the median age of women and men in the first regular smoking was 16 and 17, respectively. However, the minimum age for regular smoking was 12 years for men and 15 years for women (Fig. 1).

According to independent sample t-test, in terms of age of becoming smoker, the difference between males and females $(P<0.001)$, single and married students $(p=0.03)$, consumption and nonconsumption of alcohol in the last 30 days $(p<0.001)$, substance abuse and non-substance abuse $(p=$ $0.008)$, have and not have self-injury ( $p=0.031)$, was statically significant. Levene's test showed the heterogeneity of variance of age groups $(p<0.001)$, therefore to compare the mean age of becoming 
smokers in different age groups, the generalized ANOVA test, Welch, was used. As a result, there was a substantial difference in the age at which people started smoking between different age groups. $(p<$ 0.001). The Games-Howell post hoc test also revealed that there is a substantial difference between all age groups., except for the age group $\geq 30$ years with the age group of 26 to 30 years, which were not significantly different in terms of the age of becoming a smoker. We also found that, according to the Welch test, there is a substantial difference in the age at which people start smoking between different educational levels. Besides, the Games-Howell post-hoc test results showed that the age of becoming a smoker varies at different levels of education, and the difference was statistically significant except for associate students compared to undergraduate students; master students compared to doctorates. Also, the results of the ANOVA test showed that the average age of becoming smoker among different levels of hookah consumption is different $(p=0.002)$; The results of Hochberg's GT2 post hoc test showed that the mean age of becoming a smoker among those who smoked hookah regularly compared to those who had never smoked hookah $(p=0.023)$, and those who had just experienced it $(p=0.006)$ was significantly different (Table 3). 
Table 3

Comparison of 'age of becoming smoker' and other related factors based on demographic characteristics

\begin{tabular}{|c|c|c|c|}
\hline Variables & Mean (SD) & Median (min-max) & p-value \\
\hline Gender & & & $<0.001$ \\
\hline Male & $18.6(2.5)$ & $18.0(12-28)$ & \\
\hline female & $19.9(2.9)$ & $20.0(12-35)$ & \\
\hline Age group & & & $<0.001$ \\
\hline$<20$ & $16.94(1.40)^{\mathrm{a}}$ & $17.0(12-19)$ & \\
\hline $20-25$ & $18.46(2.15)^{b}$ & $19.0(12-24)$ & \\
\hline $25-30$ & $20.53(3.02)^{c}$ & $20.0(13-28)$ & \\
\hline$>30$ & $21.46(4.40)^{\mathrm{C}}$ & $20.0(12-35)$ & \\
\hline Marital status & & & 0.03 \\
\hline Single & $18.71(2.50)$ & $19.0(12-29)$ & \\
\hline Married & $19.72(3.57)$ & $19.0(14-35)$ & \\
\hline Education level & & & $<0.001$ \\
\hline Associate & $17.70(1.94)^{\mathrm{a}}$ & $17.0(15-25)$ & \\
\hline Undergraduate & $18.44(2.38)^{a}$ & $18.0(12-35)$ & \\
\hline Postgraduate & $20.58(3.27)^{b}$ & $20.0(12-29)$ & \\
\hline Doctorate (Ph.D. \& MD) & $19.62(2.24)^{b}$ & $20.0(14-26)$ & \\
\hline Hookah smoking & & & 0.002 \\
\hline Never & $19.45(2.57)^{\mathrm{a}}$ & $20.0(12-29)$ & \\
\hline Experimenter & $18.95(2.59)^{b}$ & $19.0(12-35)$ & \\
\hline Regular (at least once per month) & $18.36(2.60)^{\mathrm{C}}$ & $18.0(12-26)$ & \\
\hline Smoker in family & & & 0.867 \\
\hline Yes & $18.77(2.72)$ & $18.0(12-29)$ & \\
\hline No & $18.80(2.53)$ & $19.0(12-35)$ & \\
\hline
\end{tabular}

a,b,c: Dissimilar letters indicate a significant difference 


\begin{tabular}{|lccc|}
\hline Variables & Mean (SD) & Median (min-max) & p-value \\
\hline Alcohol consumption (in the last 30 days) & & & $<0.001$ \\
Yes & $18.22(2.48)$ & $18.0(12-29)$ & \\
No & $19.08(2.62)$ & $19.0(12-35)$ & \\
Substance abuse (ever) & & & 0.008 \\
Yes & $18.47(2.62)$ & $18.0(12-29)$ & \\
No & $18.98(2.60)$ & $19.0(12-35)$ & \\
\hline Self-injury & & & \\
Yes & $18.54(2.56)$ & $18.0(12-35)$ & \\
\hline No & $18.93(2.63)$ & $19.0(12-29)$ & \\
\hline a,b,c: Dissimilar letters indicate a significant difference & & \\
\hline
\end{tabular}

The effect of demographic characteristics and other related factors on the age of becoming a smoker based on linear regression model are shown in Table 4. According to the results, for one-year increase in age, the average age of becoming smoker increases by 0.2 years $(p<0.001)$ by adjusting other variables. Furthermore, by adjusting other variables, the average age of becoming a smoker in men is 0.77 years less than women $(p<0.001)$. Besides, Students who are single (unmarried) have become smokers 0.77 years later on average than married ones $(p=0.004)$. Undergraduate students compared to doctoral students have become smokers on average 0.50 years earlier $(p=0.020)$. Importantly, for one-year increase in the average age of smoking initiation, the average age of becoming a smoker increases by 0.54 years $(p<0.001)$. 
Table 4

Association of related factors with 'age of becoming smoker' based on linear regression model among the participants

\begin{tabular}{|c|c|c|c|}
\hline Variable (s) & $\beta$ (SE) & $95 \% \mathrm{Cl}$ & P-value \\
\hline Age(years) & $0.20(0.03)$ & $(0.15,0.25)$ & $<0.001$ \\
\hline \multicolumn{4}{|l|}{ Gender } \\
\hline Male & $-0.77(0.18)$ & $(-1.12,-0.42)$ & \multirow[t]{2}{*}{$<0.001$} \\
\hline Female & Ref. Category & & \\
\hline \multicolumn{4}{|l|}{ Marital status } \\
\hline Single & $0.77(0.27)$ & $(0.24,1.31)$ & \multirow[t]{2}{*}{0.004} \\
\hline Married & Ref. Category & & \\
\hline \multicolumn{4}{|l|}{ Education level } \\
\hline Associate & $-0.48(0.48)$ & $(-1.41,0.46)$ & 0.318 \\
\hline Undergraduate & $-0.50(0.21)$ & $(-0.92,-0.08)$ & 0.020 \\
\hline Postgraduate & $0.10(0.27)$ & $(-0.44,0.63)$ & 0.723 \\
\hline Doctorate (referent) & Ref. Category & & \\
\hline \multicolumn{4}{|l|}{ Hookah smoking } \\
\hline Never & $-0.19(0.30)$ & $(-0.78,0.40)$ & 0.525 \\
\hline Experimenter & $-0.03(0.14)$ & $(-0.31,0.25)$ & 0.821 \\
\hline Regular (at least once per month) & Ref. Category & & \\
\hline \multicolumn{4}{|l|}{ Smoker in family } \\
\hline Yes & $0.22(0.13)$ & $(-0.04,0.47)$ & 0.102 \\
\hline No & Ref. Category & & - \\
\hline \multicolumn{4}{|c|}{ Alcohol consumption (in the last 30 days) } \\
\hline Yes & $-0.05(0.14)$ & $(-0.33,0.23)$ & 0.714 \\
\hline No & Ref. Category & & - \\
\hline \multicolumn{4}{|l|}{ Substance abuse (ever) } \\
\hline Yes & $-0.23(0.14)$ & $(-0.50,0.04)$ & 0.089 \\
\hline No (referent) & Ref. Category & & - \\
\hline
\end{tabular}




\begin{tabular}{|llll|}
\hline Variable (s) & $\boldsymbol{\beta}(\mathrm{SE})$ & $\mathbf{9 5 \%} \mathbf{C l}$ & P-value \\
\hline Yes & $0.14(0.14)$ & $(-0.13,0.41)$ & 0.304 \\
\hline No & Ref. Category & & \\
\hline Age of inanition smoking & $0.54(0.02)$ & $(0.50,0.59)$ & $<0.001$ \\
\hline
\end{tabular}

\section{Discussion}

According to the findings of this study, students start smoking at an average age of 19 years, with males starting at a younger age than females. (18.6 vs. 19.9). It was consistent with the findings of previous studies, which indicated that adults usually become regular smokers between the ages of 18 and 21 (14). We also found that the age of becoming a smoker among older smoker students is higher than younger ones. To be more exact, younger students have become smokers at earlier ages than older students. One possible reason for the younger age of becoming a smoker can be due to the gradual disappearance of taboos and obscenity of smoking and change it to a social norm in society (23). Today, adolescents smoke more easily than their peers in the past because they have more individual and social freedoms than in the past. More smoking, and more exposure to cigarettes, may lead to more odds of becoming a smoker at an early age. Rapidly expanding telecommunications technologies that facilitate the familiarity with the culture of other countries can be the other reason for reducing the age of smokers. In a period when people, especially teenagers, are easily connecting with their peers on the Internet in other countries with different cultures, where smoking restrictions may be less severe, or cigarette advertising is not prohibited, encounter cigarette smoking as a habit can be a negative side of such cross-cultural exchange. Watching foreign movies can have a similar effect as well. Teenagers who watch films showing actors smoking are more likely to take it up as a sense of identity and social status $(24,25)$. More cigarette distribution could be another reason to increase cigarette consumption and reduce the age of smoking. With the increase of cigarette shopping areas, almost all supermarkets, and retail stores, teenagers have much easier access to cigarettes than did the generations before $(26,27)$. Early exposure to tobacco products among teenagers could reduce the age of becoming a smoker. A study carried out in the United States showed that people are less likely to start smoking regularly at an older age (10).

We also found that male students become smokers at a younger age than female students. Previous studies, especially in developing countries, have shown that males are more likely to show high-risk health behaviors and smoking $(28,29)$. According to a study of a sample of high school students in the United States, smoking initiation happens earlier among boys compared to girls (30). In Iran, parents are more protective of a daughter than a son, and also cigarette consumption by girls is socially and morally unacceptable. This could be a potential explanation for why boys are more likely to be involved in smoking than girls in Iran.

The results of our research also showed that single students become smokers at older ages than married students. Married individuals may be more inclined to smoke due to the stress and anxiety caused by 
married life (31). Stress and anxiety increase the risk for nicotine dependence and make individuals regular smokers (32). It should also be noted that married students may be more likely to buy cigarettes than single students due to their financial abilities, considering the definition of smoker in the present study where an individual buys cigarette for personal consumption. The results of our study also showed that undergraduate students become smokers at a younger age than doctoral students; This may be due to the deterrent role of higher education in preventing smoking and, ultimately, becoming smokers (3335).

Our findings have revealed a direct and important relationship between the age of being a smoker and the age of smoking initiation. Meaning that the younger individuals start smoking, the younger they become a smoker and vice versa. This was in line with previous studies that indicated the odds of becoming a smoker for those who initiate smoking at early ages is higher than those with later onset $(15,30,36)$.

\subsection{Limitations}

Low response rate is a big concern in web-based studies $(37,38)$ like ours. Furthermore, it is unclear how many students obtained the survey link but did not complete it.; hence the response rate cannot be calculated exactly. Secondly, the other limitation of web-based studies is participation bias, which makes the study non-representative (39). In our study, only those who had access to the Internet, email account, and consented to participate in this research answered the questionnaire.

\section{Conclusion}

The age of becoming a smoker has decreased over time, and people become smokers earlier than their peers in the past. In a society where the age of becoming a smoker has decreased, the age of smoking initiation has already decreased as well. By knowing the age of becoming a smoker, prevention programs can be focused on the age groups that are in the critical period of their life. We suggest that smoking prevention programs should be implemented on younger adolescents. Making School students aware and warning them about smoking and its related consequences in the textbooks could be an effective method to reduce the risk of becoming a smoker.

\section{Abbreviations}

OR: Odds ratio; Cl: Confidence Interval; P: P-value;

\section{Declarations}

\section{Acknowledgments}

The authors wish to thank all the participants who actively participated in this study for their valuable cooperation and responses. 


\section{Authors' contributions}

All authors. Study conduct: PH, FS, and AM. Data collection: PH, FS. Data analysis: NG and PH. Data interpretation: All authors. Drafting manuscript: NG, PH, and FS. Revising manuscript and content: NG and $\mathrm{PH}$. Approving final version of manuscript: All authors. NG takes responsibility for the integrity of the data analysis. VKC edited the manuscript and provided critical comments.

\section{Funding}

There was no external funding of this study.

\section{Availability of data and material}

The data gathered during the current study are not publicly available due to protections of confidentiality.

Declarations Ethics approval and consent to participate

\section{Consent to publication}

Not applicable

\section{Ethics approval and consent to participate}

Ethical approval was obtained from the Ethics Committee in Tabriz University of Medical Sciences (Ethical code: IR.TBZMED.REC.1398.190). All participant signed an informed consent. the authors declare that they have no competing interests

\section{Competing interests}

The authors declare that they have no competing interest

\section{Author contributions}

Study design: All authors. Study conduct: PH, FS, and AM. Data collection: PH, FS. Data analysis: NG and $\mathrm{PH}$. Data interpretation: All authors. Drafting manuscript: NG, PH, and FS. Revising manuscript and content: NG and PH. Approving final version of manuscript: All authors. NG takes responsibility for the integrity of the data analysis. VKC edited the manuscript and provided critical comments.

\section{References}

1. Organization WH. WHO report on the global tobacco epidemic, 2019: Offer help to quit tobacco use: World Health Organization; 2019.

2. Rink M, Shariat SF. Re: Global effects of smoking, of quitting, and of taxing tobacco. European urology. 2014;66(1):176-8. 
3. Lantz PM. Smoking on the rise among young adults: implications for research and policy. Tobacco control. 2003;12(suppl 1):i60-i70.

4. Barrington-Trimis JL, Braymiller JL, Unger JB, McConnell R, Stokes A, Leventhal AM, et al. Trends in the age of cigarette smoking initiation among young adults in the US From 2002 to 2018. JAMA network open. 2020;3(10):e2019022-e.

5. Organization WH. WHO global report on trends in prevalence of tobacco smoking 2000-2025: World Health Organization; 2018.

6. Sarraf-Zadegan N, Boshtam M, Shahrokhi S, Naderi GA, Asgary S, Shahparian M, et al. Tobacco use among Iranian men, women and adolescents. The European Journal of Public Health. 2004;14(1):768.

7. Robinson S, Harris H, Dunstan S. Smoking and drinking among adults, 2009. Newport: Office for National Statistics. 2011.

8. Oyston J. A fresh approach to tobacco control: raising the minimum legal age for access. CMAJ. 2017;189(8):E293-E4.

9. Bonnie RJ, Stratton K, Kwan LY. Public health implications of raising the minimum age of legal access to tobacco products: National Academies Press Washington, DC; 2015.

10. Ali FRM, Agaku IT, Sharapova SR, Reimels EA, Homa DM. Peer Reviewed: Onset of Regular Smoking Before Age 21 and Subsequent Nicotine Dependence and Cessation Behavior Among US Adult Smokers. Preventing chronic disease. 2020;17.

11. Fanshawe TR, Halliwell W, Lindson N, Aveyard P, Livingstone-Banks J, Hartmann-Boyce J. Tobacco cessation interventions for young people. Cochrane Database Syst Rev. 2017;11(11):Cd003289.

12. Khuder SA, Dayal HH, Mutgi AB. Age at smoking onset and its effect on smoking cessation. Addictive behaviors. 1999;24(5):673-7.

13. Hammond D. Smoking behaviour among young adults: beyond youth prevention. Tobacco control. 2005;14(3):181-5.

14. Health USDo, Abuse HSS, Statistics MHSACfBH, Quality. National Survey on Drug Use and Health, 2014. Inter-university Consortium for Political and Social Research [distributor]; 2016.

15. Reidpath DD, Davey TM, Kadirvelu A, Soyiri IN, Allotey P. Does one cigarette make an adolescent smoker, and is it influenced by age and age of smoking initiation? Evidence of association from the US Youth Risk Behavior Surveillance System (2011). Preventive medicine. 2014;59:37-41.

16. Ghodsi H, Mokhtari Lake N, Asiri S, Kazem Nezhad Leili E. Prevalence and correlates of cigarette smoking among male students of Guilan University of Medical Sciences. Journal of Holistic Nursing and Midwifery. 2012;22(1):38-43.

17. Ayatollahi S, Mohammedpoor A, Rajaee A. Determination of the prevalence of stages in cigarette smoking and its correlates in grade-10 male students in Shiraz, 2003. Journal of Mazandaran University of Medical Sciences. 2004;14(43):64-72. 
18. Kaplan CP, Nápoles-Springer A, Stewart SL, Pérez-Stable EJ. Smoking acquisition among adolescents and young Latinas: the role of socioenvironmental and personal factors. Addictive behaviors. 2001;26(4):531-50.

19. World Health Organization. Noncommunicable D, Mental Health C. World Health Organization : process for a global strategy on diet, physical activity and health. Geneva: World Health Organization; 2003.

20. Organization WH, Control RfIT. WHO report on the global tobacco epidemic, 2008: the MPOWER package: World Health Organization; 2008.

21. Hoffman JH, Welte JW, Barnes GM. Co-occurrence of alcohol and cigarette use among adolescents. Addictive behaviors. 2001;26(1):63-78.

22. Berg CJ, Parelkar PP, Lessard L, Escoffery C, Kegler MC, Sterling KL, et al. Defining "smoker": college student attitudes and related smoking characteristics. Nicotine \& Tobacco Research. 2010;12(9):9639.

23. Alesci NL, Forster JL, Blaine T. Smoking visibility, perceived acceptability, and frequency in various locations among youth and adults. Preventive medicine. 2003;36(3):272-81.

24. Roohafza H, Sadeghi M, Shahnam M, Shokouh P, Teimori S, Amirpour A, et al. Social norms of cigarette and hookah smokers in Iranian universities. ARYA atherosclerosis. 2013;9(1):45.

25. Pechmann C, Shih C-F. Smoking scenes in movies and antismoking advertisements before movies: effects on youth. Journal of Marketing. 1999;63(3):1-13.

26. Nazarzadeh M, Bidel Z, Ayubi E, Bahrami A, Jafari F, Mohammadpoorasl A, et al. Smoking status in Iranian male adolescents: A cross-sectional study and a meta-analysis. Addictive behaviors. 2013;38(6):2214-8.

27. Niknami S, Akbari M, Ahmadi F, Babaee Rouchi G, Heidarnia A. Smoking initiation among Iranian adolescents: a qualitative study. EMHJ-Eastern Mediterranean Health Journal, 14 (6), 1290-1300, 2008. 2008.

28. Karadoğan D, Önal Ö, Kanbay Y. Prevalence and determinants of smoking status among university students: Artvin Çoruh University sample. PloS one. 2018;13(12):e0200671.

29. Shekari F, Habibi P, Nadrian H, Mohammadpoorasl A. Health-risk behaviors among Iranian university students, 2019: a web-based survey. Archives of Public Health. 2020;78(1):1-6.

30. Sharapova S, Reyes-Guzman C, Singh T, Phillips E, Marynak KL, Agaku I. Age of tobacco use initiation and association with current use and nicotine dependence among US middle and high school students, 2014-2016. Tobacco Control. 2020;29(1):49-54.

31. Fluharty M, Taylor AE, Grabski M, Munafò MR. The association of cigarette smoking with depression and anxiety: a systematic review. Nicotine \& Tobacco Research. 2016;19(1):3-13.

32. Holliday E, Gould TJ. Nicotine, adolescence, and stress: a review of how stress can modulate the negative consequences of adolescent nicotine abuse. Neuroscience \& Biobehavioral Reviews. 2016;65:173-84. 
33. Tomioka K, Kurumatani N, Saeki K. The association between education and smoking prevalence, independent of occupation: a nationally representative survey in Japan. Journal of epidemiology. 2020;30(3):136-42.

34. Jamal A, Homa DM, O'Connor E, Babb SD, Caraballo RS, Singh T, et al. Current cigarette smoking among adults-United States, 2005-2014. Morbidity and mortality weekly report. 2015;64(44):123340.

35. Solberg LI, Asche SE, Boyle R, McCarty MC, Thoele MJ. Smoking and cessation behaviors among young adults of various educational backgrounds. American Journal of Public Health. 2007;97(8):1421-6.

36. Hwang JH, Park S-W. Age at smoking initiation and subsequent smoking among Korean adolescent smokers. Journal of Preventive Medicine and Public Health. 2014;47(5):266.

37. Ebert JF, Huibers L, Christensen B, Christensen MB. Or web-based questionnaire invitations as a method for data collection: cross-sectional comparative study of differences in response rate, completeness of data, and financial cost. Journal of medical Internet research. 2018;20(1):e24.

38. So R, Shinohara K, Aoki T, Tsujimoto Y, Suganuma AM, Furukawa TA. Effect of recruitment methods on response rate in a web-based study for primary care physicians: factorial randomized controlled trial. Journal of medical Internet research. 2018;20(2):e28.

39. Van Gelder MM, Bretveld RW, Roeleveld N. Web-based questionnaires: the future in epidemiology? American journal of epidemiology. 2010;172(11):1292-8.

\section{Figures}

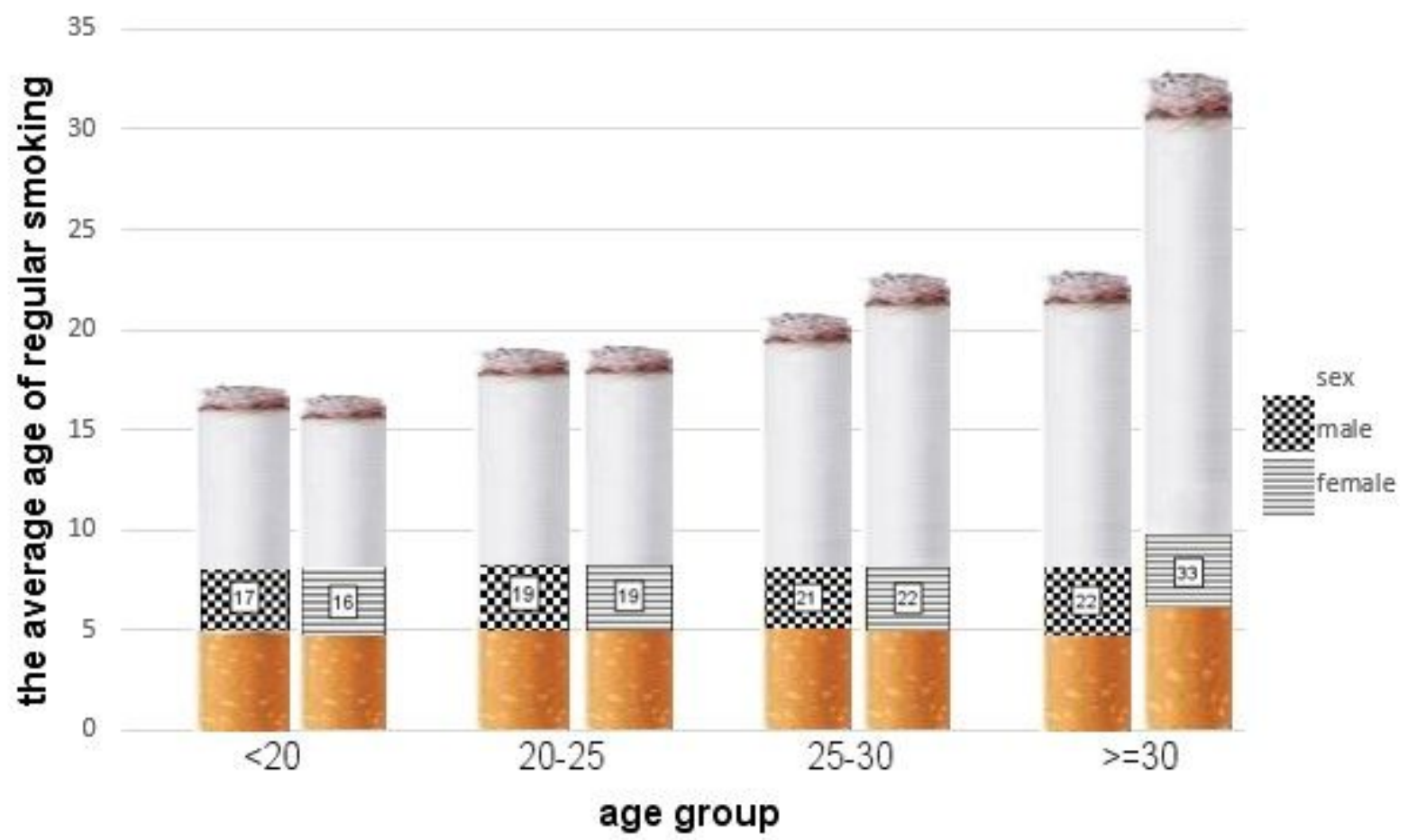




\section{Figure 1}

The age trend of regular smoking among students over time by gender 